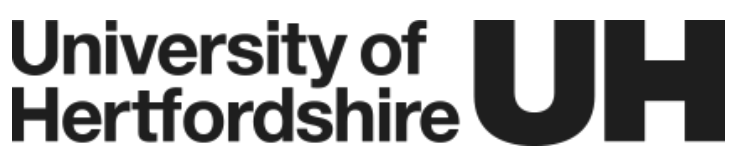

\section{Citation for the published version:}

Benasla, M., Allaoui, T., Brahami, M., Sood, V., \& Denai, M. (2019). Power system security enhancement by HVDC links using a closed-loop emergency control. Electric Power Systems Research, 168, 228-238. https://doi.org/10.1016/j.epsr.2018.12.002

Document Version: Accepted Version

This manuscript is made available under the CC-BY-NC-ND license https://creativecommons.org/licenses/by-nc-nd/4.0/

\section{Link to the final published version available at the publisher: https://doi.org/10.1016/j.epsr.2018.12.002}

\section{General rights}

Copyright $\odot$ and Moral Rights for the publications made accessible on this site are retained by the individual authors and/or other copyright owners.

Please check the manuscript for details of any other licences that may have been applied and it is a condition of accessing publications that users recognise and abide by the legal requirements associated with these rights. You may not engage in further distribution of the material for any profitmaking activities or any commercial gain. You may freely distribute both the url (http://uhra.herts.ac.uk/) and the content of this paper for research or private study, educational, or not-for-profit purposes without prior permission or charge.

\section{Take down policy}

If you believe that this document breaches copyright please contact us providing details, any such items will be temporarily removed from the repository pending investigation.

\section{Enquiries}

Please contact University of Hertfordshire Research \& Scholarly Communications for any enquiries at rsc@herts.ac.uk 


\title{
Power system security enhancement by HVDC links using a closed-loop emergency control
}

\author{
Mokhtar Benasla $^{\mathrm{a}, *}$, Tayeb Allaoui ${ }^{\mathrm{a}, \mathrm{b}}$, Mostefa Brahami ${ }^{\mathrm{c}, \mathrm{d}}$, Vijay K. Sood ${ }^{\mathrm{e}}$, and Mouloud Denaii ${ }^{\mathrm{f}}$ \\ ${ }^{a}$ L2GEGI Laboratory, Tiaret, Algeria \\ ${ }^{b}$ Department of Electrical Engineering, Ibn Khaldoun University, Tiaret, Algeria \\ ${ }^{c}$ Department of Electrotechnics, Djillali Liabes University, Sidi Bel Abbes, Algeria \\ ${ }^{d}$ ICEPS Laboratory, Sidi Bel Abbes, Algeria \\ ${ }^{e}$ University of Ontario Institute of Technology, Oshawa, ON. Canada. \\ ${ }^{f}$ School of Engineering and Technology, Hertfordshire University, Hatfield, U.K \\ *Corresponding author. Email: benasla.mokhtar@yahoo.fr
}

\begin{abstract}
In recent years, guaranteeing that large-scale interconnected systems operate safely, stably and economically has become a major and emergency issue. A number of high profile blackouts caused by cascading outages have focused attention on this issue. Embedded HVDC (High Voltage Direct Current) links within a larger AC power system are known to act as a "firewall" against cascading disturbances and therefore, can effectively contribute in preventing blackouts. A good example is the 2003 blackout in USA and Canada, where the Québec grid was not affected due to its HVDC interconnection. In the literature, many works have studied the impact of HVDC on the power system stability, but very few examples exist in the area of its impact on the system security. This paper presents a control strategy for HVDC systems to increase their contribution to system security. A real-time closedloop control scheme is used to modulate the DC power of HVDC links to alleviate AC system overloads and improve system security. Simulations carried out on a simplified model of the Hydro-Québec network show that the proposed method works well and can greatly improve system security during emergency situations.
\end{abstract}

Keywords: HVDC; AC/DC interconnection; DC power modulation; Blackout risk; emergency control; closed-loop control.

\section{Introduction}

Power system security refers to the ability of the system to withstand contingencies without violating the specified operating limits (i.e. bus voltages, line loadings, etc.) or compromising its post-contingency stability. Usually security levels are evaluated according to certain deterministic criteria by performing contingency analysis. If one or more contingencies would result in violations of the operational constraints or would make the system unstable, control actions should be taken to preserve system security. Traditionally, two types of controls have 
been used to ensure system security: preventive control and emergency control [1,2]. Preventive control seeks to adjust the operating conditions for the power system to operate within sufficient margins of a defined set of static and dynamic constraints. This will enable the system to cope with future events (given by a set of most credible contingencies) without any additional postcontingency control. Preventive control requires significant standby reserves, and therefore incurs higher operating costs [1,3]. Emergency control, on the other hand, acts in the postcontingency state, i.e. after the contingency has occurred, which makes it possible to minimize the reserves required and consequently the operation costs [1,2,4-12]. Although, with emergency control the operating costs are significantly reduced, most utilities around the world still rely on preventive control to maintain the security of their systems at an acceptable level. In fact, several emergency control schemes have been designed and installed worldwide in the past, but these schemes have been used only as an additional line of defense and were prevented, as much as possible, from operating by applying preventive control actions [1]. This is because these emergency control schemes, also called special protection schemes or remedial action schemes, have several disadvantages including complexity, high costs and the provision of control over predefined events only (i.e. feed-forward type). Some of these emergency controls involve the disconnection of the customer's electricity supply $[13,14]$. However, several drivers, such as those listed below, are motivating the use of corrective controls in the future to ensure secure operation of power systems $[1,2,5,13,14]$.

- The increased difficulty in constructing new transmission lines (i.e. difficulty of obtaining rights of way to build new overhead lines) which forces Transmission System Operators (TSOs) to maximize the use of existing infrastructures to meet the growing power demand.

- Increased penetration of intermittent and variable renewable energy resources increases uncertainty in the power system's operation, making it more difficult for TSOs to fulfill the $\mathrm{N}-1$ criterion without recourse to emergency controls. 
- Increased adoption of HVDC links and flexible AC transmission systems (FACTS) devices which offer new solutions for designing faster and more efficient emergency controls.

- The recent rapid development of wide area measurement systems (WAMSs) based on phasor measurement units (PMUs), already been deployed in several countries, offers the possibility to design closed-loop emergency control schemes (i.e. feedback type) that can respond to any arbitrary disturbances.

One of the common scenarios in the previous blackouts is the overloading and tripping of transmission lines in a cascading sequence due to the power redistribution phenomenon [13]. Due to the first two factors mentioned above, relieving system overloads has become one of the biggest challenges for TSOs. Several techniques have been proposed in the literature to relieve overloads in power systems, such as generation re-dispatch, load shedding and power flow redistribution through transmission line switching or power flow controlling devices (phase shifting transformers, HVDC, FACTS) [5-12,14-32]. Owing to the above disadvantages of emergency controls, power flow redistribution by HVDC and FACTS is considered to be the most promising and preferred approach available to utilities to relieve overload in modern power systems compared with other corrective control techniques [33]. This strategy is promising because HVDC and FACTS technologies can achieve fast and reliable overload relief using feedback control techniques which are well suited for systems with uncertainties. The strategy is preferred because of its economic benefits since it avoids the economic penalties incurred when using other strategies such as generation re-dispatch and load shedding.

HVDC technology is now well established and widely used worldwide for bulk electricity transmission, long-distance transmission and asynchronous interconnection. One of the most important specific advantages of HVDC technology is its ability to dynamically isolate an area of the grid from the rest of the system, and therefore can serve as an automatic firewall against cascading disturbances thus preventing large-scale blackouts [13,34,35]. A good example is the 
2003 blackout in USA and Canada, where the Québec grid was not affected by the outage due to its HVDC interconnection to the US, whereas the neighboring province of Ontario (synchronous interconnection with US) was fully affected [36]. It is worth mentioning that this specific advantage of HVDC systems is only limited to asynchronous interconnections. However, in several regions around the world, the development of power systems is clearly focused towards the hybrid interconnection [37]. Clearly, new means to improve the security of hybrid interconnection systems using HVDC links are highly desirable.

To effectively exploit the high controllability of HVDC systems, this paper develops a control strategy to improve the security of hybrid interconnection systems during emergency situations. The HVDC link is used to relieve, in real-time, the transmission system overloads by means of a supplementary closed-loop control scheme.

Currently, the only available method to calculate control set-points of HVDC links (or FACTS devices) to relieve overload on a transmission line requires knowledge of the sensitivities of this line with respect to HVDC (or FACTS devices) controls. However, transmission lines sensitivities calculation in real-time is time-consuming and relies heavily on the fast acquisition and processing of accurate and reliable data which poses a major challenge. With the proposed control approach, transmission line loading can be reduced to the desired level without the need to calculate the sensitivities indices, which makes possible the implementation of emergency control. It is hoped that this contribution will stimulate further work in this emerging and exciting area of research.

\section{Preliminary Analysis}

Detailed analysis of previous blackouts has shown that they originate from cascading events in which a triggering failure (e.g., line fault or loss of a power plant) produces a sequence of secondary failures that lead to the blackout of a large area of the grid $[13,38,39]$. To ensure that a single contingency does not result in cascading outages, some deterministic security rules are applied. A common practice is the so-called $\mathrm{N}-1$ criterion which can be defined as follows: the 
system should always be operated with a sufficient security margin in such a way that it is able to withstand any credible contingency (e.g. outage of a line) without any additional control action. System operators continually perform contingency analysis at the operation point to determine if the system is secure for all credible contingencies. To speed up the computation, a screening process is usually used to determine the critical contingencies from the entire set of credible contingencies.

As mentioned previously, it is becoming difficult for today's power systems to ensure security by applying preventive control, as highlighted in several reports on previous blackouts where the no fulfillment of the $\mathrm{N}-1$ criterion was considered as the major cause [40,41].

Consequently, emergency control has been proposed as an additional line of defense to reduce the excessive use of preventive actions, especially because most credible contingencies (equipment outages) are relatively rare events [10]. In emergency control, the system operates without fulfillment of the strict N-1 criterion, but relies on corrective actions after the occurrence of any outage, in other words the control action is triggered only if the predefined event occurs. This situation is called the corrective $\mathrm{N}-1$ security criterion. As an example, the Swiss power system was operated according to this criterion before the Italian blackout of September 2003 [13,41]. Emergency control can reduce the system operating cost, while providing the same security level as preventive control [1-10]. To illustrate this, the simple example of Fig. 1 is used. In this system, Areas A and B are connected through three AC lines and one parallel DC line. The AC lines are identical and have a capacity of $300 \mathrm{MW}$ each. A load of $1700 \mathrm{MW}$ is connected in Area B. The rated power of the bipolar HVDC link is 500 MW. The generators in Areas A (capacity 2000 MW) and B (capacity 1500 MW) are used to supply the load. If the incremental costs in Area A is $20 \$ / \mathrm{MWh}$, and that of area B is 50 \$/MWh, the pure economic dispatch solution would be as shown in Fig. 1(a) and the total operating cost would be equal to $43000 \$ / \mathrm{h}$. 
Suppose now that the $\mathrm{N}-1$ criterion is applied to improve system security to an acceptable level, therefore, the system should have no overloads if one of the AC lines fails (the outage of an HVDC pole is also considered). The resulting line flows will be as shown in Fig. 1(b). Clearly, this security-constrained dispatch has a higher operating cost (52000 \$/h) than the pure economic dispatch shown in Fig. 1(a).

Now, suppose that the generators in Areas A and B can increase/decrease their power outputs by $100 \mathrm{MW}$ before the system protection is triggered. Considering the advantage of the postdisturbance corrective action after the outage, the dispatch shown in Fig. 1(c) is obtained. Thus, it is possible to achieve the same level of security as in the dispatch obtained with the preventive method, but with a lower operating cost of $49030 \$ / \mathrm{h}$.

It is well known that the HVDC link can transmit more than the rated power for short periods of time (and sometimes even for longer periods under special circumstances). Suppose that the 500 MW HVDC link considered in our example has a continuous overload capability of $20 \%$ (i.e. $100 \mathrm{MW}$ ). When one pole is lost, the power transfer in the remaining pole is $250 \mathrm{MW}$, with a continuous overload capability of $50 \mathrm{MW}$. Due to its controllability and its overload capability, the HVDC can be used as an emergency measure to protect the parallel AC lines from being overloaded by increasing its transmitted power [34,42-45]. Taking this corrective action into account, the same dispatch shown in Fig. 1(c) is obtained. As opposed to generation re-dispatch which incurs considerable cost, the corrective action by the HVDC link comes at zero cost. Since the use of re-dispatching generation to eliminate constraint violations always comes at a cost, the primary concern in this corrective action is to re-dispatch the leastexpensive generation. However, this objective increases the complexity of decision making process which may lead to more generation shedding than what is needed. Thus, the overload capability of the HVDC link is the most cost-effective solution as it can minimize or even eliminate the need for generation re-dispatch outside the preferred schedules. Therefore, HVDC links can be used, as a first step, to eliminate constraint violations during certain contingencies 
thus avoiding costly generation re-dispatch. If, however, this corrective action is not sufficient to move the operating point to a secure state, then additional actions (probably costlier) may be considered.

A review of past blackouts shows that one of the main causes of cascading outages was due to a lack of information about system conditions and a lack of preparedness to take decisive and appropriate corrective actions $[13,38]$. Thus, automatic execution of power flow control actions is a key solution to such problems. To achieve this objective, real-time closed-loop control schemes are required, which are believed to provide reliable results and reduce the risk of human error. Online Dynamic Security Assessment (DSA) is an ideal tool for such a task where transfer limits can be calculated using real-time data. These objectives can be achieved with the recent rapid development of wide-area monitoring systems based on Phasor Measurement Units (PMUs) which are already installed in many sites worldwide [1,33].

Fast response is crucial for any corrective control, especially for high overloading conditions which should be resolved quickly. In the simple example of Fig. 1, if one AC line is out of service and the HVDC power is not quickly increased, the remaining AC lines are likely to be immediately disconnected by their protection systems. After the second outage, an increase in HVDC power cannot prevent the outage of the third line because of insufficient overload capability of the HVDC link. Thus, there is only a short time interval during which HVDC power must be increased before the overload protection triggers, as may be the case when the operator is unavailable or not experienced enough to react quickly and accurately [10]. Usually, a power flow control action initiated by an operator in an interconnected system can take about twenty minutes or more [1]. Therefore, automated decision making with little or no human intervention is essential to avoid widespread cascading developments in today's highly stressed interconnected power systems. This was one of the major recommendations that have been summarized in some technical reports made by teams of experts to reduce the risk of blackouts in the future $[13,38,36,40,41]$. 
To the best of our knowledge, little or no work addressing the relief of line overloads by HVDC links using a real-time closed-loop control scheme has been reported in the literature. Only methods based on the supplementary controls for HVDC power modulation have been proposed for transient stability improvement and damping of power oscillations. In the next section, a supplementary HVDC control for relieving overloads of transmission lines is presented.

\section{Proposed control strategy}

\subsection{HVDC system}

The HVDC system considered in this paper is of the conventional line-commutated converter (LCC) type based on thyristor valves. By controlling the firing angle for the rectifier $\alpha_{R}$, the power through the HVDC link can be controlled by a current controller (Fig. 2). The limited current reference $I_{\text {ref_lim }}$ is generated using the Voltage Dependent Current Limit (VDCL) unit which provides current reference values during steady-state and transient conditions. The VDCL has a fast-acting response which enhances the transient stability of the integrated ACDC system. Because of its dynamic and static properties, the VDCL can respond rapidly to reduce DC power flow to a minimum (typically 20\% value) and respond slowly (on a controlled ramp rate, typically over a period of 150-350 ms) to increase DC power flow to help voltage and power recovery following faults and enhance the stability of the overall system $[54,55]$. The power transmitted by the HVDC link can be easily controlled with a high speed of response (typically, in the range of tens of milliseconds). Thus, the HVDC link can be used for stabilization of the associated AC system by modulating the HVDC power. The power flow in the HVDC link is usually modulated by adding an auxiliary signal $\left(\Delta I_{D C}\right)$ to the current reference of the rectifier controller (see Fig. 2). This modulation control signal is derived in response to the variations in some AC system quantities (external signal), such as the frequency or phase change. This technique is usually used to improve transient stability (first swing 
stability) and to damp power oscillations (dynamic stability) [45,48-51]. A discontinuous control signal can be used to improve transient stability during system disturbances, and a continuous control signal (i.e. active all the time) can be used to increase the damping.

In order to obtain an automatic real-time HVDC power control that addresses the relief of line overloads, the authors propose to introduce a discontinuous modulation control signal which can be applied during emergency situations to reduce the loading of some selected critical AC transmission lines. The objective is to accurately control the HVDC power at the right level and at the right time to remove line overloads and reduce the risk of cascading outages.

\subsection{Closed-loop control}

The HVDC link is used here to reduce the risk of cascading line outages by keeping the loading margin of some selected critical AC lines at an acceptable level during disturbances. Fig. 3 shows the power characteristics $\left(P_{1}(t)\right.$ and $\left.P_{D C}(t)\right)$ of the system considered in Fig. 1 (it should be noted that these characteristics are proposed only to explain the control strategy). $P_{C 1}$ is the power transfer limit of line 1. It is necessary to satisfy the load demand without compromising the system security. $P_{M 1}$ (margin point) is the appropriate limit on loading to ensure the secure operation of line 1 and reduce the risk of component failure due to overloading. The methodology is: whenever a line exceeds its operating margin point $P_{M i}$ (in this case line 1 at time $t_{1}$ ), then the DC power $P_{D C}$ will be automatically adjusted to keep $P_{1}$ at its margin point $\left(P_{M 1}\right)$ as shown in Fig. 3(a). $P_{D C M A X}\left(I_{D C M A X}\right)$ is specified as the upper limit for the current carrying capacity of the converter valves. Due to their limited thermal inertia, the converter valves cannot carry a current that is higher than the rated value for a long period [47]. The overload capability is subject to the thermal rating of other equipment, such as the converter transformer and smoothing reactor; it is also subject to the ambient temperature as well as the status of redundant cooling system [52]. 
An adaptive and real-time determination of the DC power changes to relieve specified overloads can be achieved with the application of the new Information and Communication Technologies (ICT) such as multi-agent systems and Wide Area Monitoring Systems (WAMS) using Phasor Measurement Units (PMU) [12,33].

When there is an overload condition (i.e. the measured line flow is greater than the specified line rating), the amount of DC power change $\Delta P_{D C i}$ required to reduce the loading on line $i$ can be determined using the following equation:

$$
\Delta P_{D C i}=\frac{\left(P_{i}-P_{M i}\right)}{S_{i}}
$$

where, $P_{i}$ is the measured power flow in line $i, P_{M i}$ is the specified power rating of line $i$ (a small security margin is introduced in our study to ensure system security) and $S_{i}$ is the sensitivity of line $i$ with respect to the change in the DC power which is written as:

$$
S_{i}=\frac{\partial P_{i}}{\partial P_{D C}}
$$

This procedure is illustrated in Fig. 3(b) for line 1. The required $\Delta P_{D C 1}$ to reduce the loading level of line 1 and maintain $P_{1}(t)$ at $P_{M 1}$ is given by $\Delta P_{D C 1}=\frac{\left(P_{1}-P_{M 1}\right)}{S_{1}}$, where $P_{1}$ is the power measured at time $t_{2}$.

However, because the determination of the control set-points of HVDC links requires real-time computations of the sensitivities of transmission lines, several uncertainties emerge during these computations. As a consequence, the application of this control technique relies on the availability of accurate and higher quality online data to be processed at the right time, which poses a major challenge for the implementation of such a technique in actual system operations $[1,53]$. Moreover, since it takes some time to collect the required information and calculate the sensitivities of the transmission lines before taking the control action, changing the HVDC setpoint is not a purely real-time control. To overcome this, a closed-loop control scheme, where 
$\Delta P_{D C}$ is determined continuously without the need to calculate the sensitivities of the transmission lines is needed.

Ignoring transmission losses, the total power transfer from Area A to Area B (Fig. 1) is given by the equation:

$$
P_{T}(t)=P_{D C}(t)+P_{1}(t)+P_{2}(t)+P_{3}(t)
$$

Where, $P_{1}(t), P_{2}(t)$ and $P_{3}(t)$ represent the power flows in lines 1,2 and 3 respectively and $P_{D C}(t)$ is the DC power of the HVDC link. When the control strategy is not in operation (i.e. the HVDC is transferring a constant amount of power), $P_{D C}(t)$ is always equal to $P_{D C}$ ref. When the power through line 1 exceeds its margin point $P_{M 1}$, the DC power is increased to maintain $P_{1}(t)$ at $P_{M 1}$ and reduce the loading level of line 1 (i.e. $P_{D C}(t) \neq P_{D C_{-} r e f}$ as illustrated by Fig. 3(a)), then we can write:

$$
P_{D C}(t)=\Delta P_{D C 1}(t)+P_{D C_{-} r e f} \quad \text { and } \quad P_{1}(t)=P_{M 1}
$$

Therefore, the total power $P_{T}(t)$ is given by:

$$
P_{T}(t)=P_{D C_{-} r e f}+\Delta P_{D C 1}(t)+P_{M 1}+P_{2}(t)+P_{3}(t)
$$

From (3) and (5), the amount of DC power increment $\Delta P_{D C 1}(t)$ required to keep $P_{1}(t)$ at $P_{M 1}$ is:

$$
\Delta P_{D C 1}(t)=\left(P_{D C}(t)-P_{D C_{-} r e f}\right)+\left(P_{1}(t)-P_{M 1}\right)
$$

This equation gives the exact value of $\Delta P_{D C}$ in a continuous fashion where the power through the line of concern (in this case line 1) is the only information needed.

In general, when the variation in the DC power of an HVDC link affects the MW flow of any transmission line in the system (line $i$ ), the power flow through this transmission line $P_{i}(t)$ can be controlled by the HVDC link at a defined point $P_{M i}$ based on the following equation

$$
\Delta P_{D C i}(t)=\left(P_{D C}(t)-P_{D C_{-} r e f}\right)+\left(P_{i}(t)-P_{M i}\right)
$$

Note that equation (7) is used when the increase in DC power leads to a decrease in the loading of line $i$ (i.e. the sign of sensitivity is negative). Conversely, when the increase in DC power 
produces an increase in the loading of line $i$ (i.e. the sign of sensitivity is positive), the following equation is used:

$$
\Delta P_{D C i}(t)=\left(P_{D C}(t)-P_{D C_{-} r e f}\right)-\left(P_{i}(t)-P_{M i}\right)
$$

The strategy is implemented by adding a control signal $\Delta I_{D C}$ to the DC current reference of the rectifier current regulator, as shown in Fig. 2.

The signal $\Delta I_{D C}$ is given by:

$$
\Delta I_{D C}=\frac{\Delta P_{D C}}{V_{D C}}
$$

where, $V_{D C}$ is the DC voltage of the HVDC link.

A block diagram of the control strategy used to protect line $i$ from overloading is depicted in Fig. 4. The measured values $\left(P_{i}\right.$ and $\left.P_{D C}\right)$ are passed through a low-pass filter to eliminate higher order harmonics. The block $B_{D i}$ is used to detect overloading (i.e. when $P_{i}$ exceeds its margin point $P_{M i}$ ). During secure operation of the line (i.e. $\left.P_{i}<P_{M i}\right) R_{i}$, the output of block $B_{D i}$ is always zero, but when the power $P_{i}$ is greater than or equal to $P_{M i}, R_{i}$ is equal to $P_{i}$. The controller is active only when line $i$ is operated close to its limit (i.e. $P_{i} \geq P_{M i}$ ) in which case there is a substantial risk of a cascading outage. As discussed above, the DC link is used here to control the power $P_{i}$ at $P_{M i}$, therefore, $P_{i}$ will vary around $P_{M i}$, and this leads to a discontinuous action of the detection block $B_{D i}$. A low-pass filter is used to remove high-frequency noise and achieve a continuous control signal. Finally, a limiter is employed to limit the maximum amplitude of the modulation signal applied to the current regulator. Like the transmission line, the generator also has a limit, and when this limit is reached, loss of generation can occur due to overloading if load shedding is not applied. With the same method, the HVDC link can be used to maintain the generation at the receiving-end at a safe level, thereby reducing the risk of load shedding. The loss of generation in Area B (Fig. 1) can be avoided with the control strategy by keeping the power generation in this area at a safe level (margin point: $P_{M B}$ ) with the following equation: 
$\Delta P_{D C B}(t)=\left(P_{B}(t)-P_{M B}\right)+\left(P_{D C}(t)-P_{D C_{-} r e f}\right)$

where $P_{B}$ is the power generation in area $\mathrm{B}$.

Remote signals will not present a problem when the proposed control is applied to a large interconnected system. For instance, back in 1976, a control system was implemented to improve the stability and damping oscillations through modulation of the Pacific HVDC Intertie using active power and later, current magnitude signals from a remote substation on the parallel Pacific AC intertie [14, 49]. In fact, modulation with remote signals has been successfully used in various HVDC projects around the world [42,43,45]. In addition, major advances in measurement and communication technologies, such as phasor measurement system and fiberoptic telecommunication, open up the possibility of using remote signals to design more efficient control schemes [1,14,54-56].

The proposed control would be applied as a discontinuous supplementary control, i.e. the remote signal $R_{i}$ (Fig. 4 ) is transmitted to the converter station only when necessary (when, $P_{i} \geq$ $\left.P_{M i}\right)$. As noted by several authors, the implementation of discontinuous supplementary controls has good prospects and the application of these controls may be, in many cases, less costly than network reinforcement [14,51,57].

\subsection{Application procedures}

As discussed above, the HVDC link can be used as a measure to reduce the loading of overloaded lines with a view to avoid or minimize the economic sanctions incurred by generation re-dispatch method. This HVDC control can be incorporated into the existing realtime corrective control programs, as shown in the flowchart of Fig. 5. To achieve the economic benefits, the corrective action with HVDC links should be applied prior to the generation redispatch procedures. If the impact of available HVDC links is not sufficient to completely eliminate the overloads, generation re-dispatch procedure should be called to relieve the remaining overloads. The main purpose of the proposed closed-loop control is to avoid the realtime intensive computations (load flow and sensitivity calculations) required for the accurate 
calculation of the control set-points of HVDC links. This is because contingencies can cause changes in the network topology and this in turn leads to changes in the sensitivity indices which need to be recalculated online. However, although sensitivity analysis is not needed to determine the required amount of DC power change in the proposed control, it is needed in the decision-making process. For example, if a line overload is detected, the HVDC link that has the largest effect on this line should be used to alleviate the overload, i.e., the HVDC that can produce the largest power flow change on the line when its DC power is increased to the maximum limit (i.e. overload capability). The power change $\Delta P_{i, k}$ that can be produced on line $i$ when the DC power of HVDC $k$ is increased to its maximum limit can be determined by the following equation:

$\Delta P_{i, k}=\left(P_{D C k}^{\max }-P_{D C k}\right) S_{i, k}$

where

$P_{D C k}$ is the actual (measured) DC power of HVDC $k$

$P_{D C k}^{\max }$ is the maximum possible DC power of HVDC $k$

$S_{i, k}$ is the sensitivity of line $i$ with respect to the control of HVDC $k$

However, since sensitivity indices are not needed to determine the required increment of the DC power and are only needed to select which HVDC link will provide this power, an off-line sensitivity analysis would be sufficient. Based on this sensitivity analysis, HVDC links are ranked according to their potential effects on line flows. An expert system such as those described in $[18,30,31,58,59]$ can be used for this purpose. Normally, each HVDC link will have a significant impact only on some neighboring lines [31]. A review on the existing hybrid AC/DC interconnection systems around the world shows that the HVDC links are used in these systems to connect major power generation facilities with main load centres where several AC transmission lines, usually referred to as tie-lines, are also used. In such systems, the HVDC links will have a significant impact on these tie-lines feeding the main loading areas. For 
example, in the system shown in Fig. 6, the red HVDC links would have a significant impact on the red AC lines (presented by red arrows), while the green HVDC links would have a significant impact on the green AC lines. In today's interconnected systems, it is very important to control the power flow on certain of these lines (tie-lines) and to ensure their secure operation. Because these lines are often operated close to their limits, a failure of one or more of these will have a significant impact on the system security as already experienced in several large blackouts in different parts of the world $[13,38]$. The HVDC links would also have an impact on some transmission lines within certain areas of the system, particularly the sendingand receiving-end areas. In the sensitivity analysis process, an appropriate threshold $S_{i, k} \geq S_{T k}$ (where $S_{T k}$ is the defined threshold for HVDC $k$ ) is considered for each HVDC link to discard the actions which would result in a minor impact on MW flow changes of some transmission lines. Thresholds are defined according to the amount of DC power change offered by each HVDC link (i.e. the capability: $P_{D C k}^{\max }-P_{D C k}$ ), in which the threshold of the HVDC link with a high capability is less than that of a HVDC link with a small capability (see equation (11)). After ranking the HVDC links, according to their effects on transmission lines in the base case situation, an analysis of the effect of $\mathrm{N}-1$ and $\mathrm{N}-2$ contingency situations on the sensitivity indices should be performed to validate the list established in the base case condition during contingency situations and to verify that the expected control actions of any HVDC link do not have any adverse effect during these contingency situations. This is because the HVDC link would reduce loading on one line but would simultaneously increase loading on another line.

When a line overload is detected, the HVDC with the largest impact on that line in the list will be used first to relieve the overload. If the overload is not eliminated, the second HVDC in the list with respect to the line (i.e. the one having the second largest impact on the line) will be used to eliminate or further reduce the overload, and so on. If the overload is not completely eliminated by the available HVDC links, generation re-dispatch procedure should be applied to resolve the issue (see Fig .5). When two or more overloaded lines are detected at the same time 
and a potential HVDC link has been identified for all these lines, an overload index $L I$ is used to determine the most critical line between them. The line with the highest value of $L I$ will be the most critical line and the identified HVDC link will act first to relive the overload on that line. The overload index of line $i$ is given by:

$$
L I_{i}=w_{i} \frac{P_{i}}{P_{M i}}
$$

where $P_{i}$ is the measured power flow in line $i, P_{M i}$ is the specified power rating of line $i$ (i.e. the limit) and $w_{i}$ is a non-negative weighting factor which may be used to reflect the importance of the line according to certain considerations such as its impact on the security and stability of the system and/or its impact on the operating cost of the system, etc. $\frac{P_{i}}{P_{m i}}$ is a measure of the violation of the limit.

After each control action, a check procedure is performed to ensure that the control is in the right direction, i.e. the loading of the line of concern should be decreasing with the change in the DC power; otherwise, the control action is turned off and another HVDC is selected according to the fixed list (see Fig. 5).

\section{Case study}

In hybrid interconnections, HVDC systems are usually constructed to transmit power over long distances from regions with high power generation resources such as coal and hydro to the main load centres with several AC transmission lines. In these systems, the proposed control will play an important role to prevent cascading outages of major AC transmission lines that cause widespread blackouts. To test and illustrate the effectiveness of our approach in such systems, a simplified model of the Hydro-Québec $735 \mathrm{kV}$ series-compensated transmission system is used. The Hydro-Québec transmission system is used to transmit over long distances (more than 1000 $\mathrm{km}$ ) bulk power generated in the north by large hydroelectric generation complexes to the load centers in the southern part of the province of Quebec (the population centers of Montreal and 
Quebec City). The simplified model used in our study is a reduced version of the real system, designed with a similar configuration to mimic load flow behaviour of the real system. In general, in the Quebec system, there are large power transfers in the North-South direction through several $735 \mathrm{kV}$ transmission lines. A single-line diagram of the studied system is given in Fig. 7. The power flow (in MW) in the base case condition is also shown in the figure. The power flow directions are indicated by arrows along the transmission lines (the powers are measured at the receiving bus of each line). A detailed description of the network model can be found in [60]. The model is also available as a demo in the MATLAB SPS software (release R2013a). The total loads used in the model for the Montreal and Quebec City areas are 15500 MW and 6000 MW respectively. The system is implemented in MATLAB SPS with a detailed model of generators. As in the real system, an HVDC link of $2000 \mathrm{MW}$ is connected between James Bay area (at bus 1) and Montreal area (at bus 8). The HVDC model considered in this paper is a monopolar link of the conventional type (see Fig. 8) based on the CIGRE benchmark system [61]. In order to ensure the reliability of the simulation test results as well as the performance of the control strategy, a detailed HVDC model is adopted. The rectifier and inverter are 12-pulse converters consisting of two 6-pulse thyristor bridges connected in series. The reactive power required by the converters is provided by a set of capacitor banks plus 11th, 13th and high pass filters on each side. A series reactor is also introduced between the two HVDC stations to smooth the DC current. Suppose that the 2000 MW HVDC link considered in our system has an overload capability of 35 \% (i.e. 700 MW).

A sensitivity analysis performed in the base case condition showed that the HVDC link has an impact on the transmission lines used to transmit the power generated in the James Bay area (sensitivities between 0.12 and 0.36 indicated by the color in the figure and shown in Table 1) but has a negligible or no impact on the lines used to transmit power generated in the Churchill and Manic areas. The analysis also showed that all the sensitivity indices have a negative sign 
except the line between buses 1 and 2 which had a positive sensitivity. These remarks have also been observed during several N-1 contingency situations.

Table 1. Sensitivity indices of transmission line

\begin{tabular}{cc}
\hline Line & Sensitivity index \\
\hline From bus 15 to bus 8 & -0.36 \\
\hline From bus 3 to bus 6 & -0.26 \\
\hline From bus 1 to bus 3 & -0.23 \\
\hline From bus 6 to bus 9 & -0.19 \\
\hline From bus 2 to bus 1 & +0.17 \\
\hline From bus 2 to bus 4 & -0.16 \\
\hline From bus 9 to bus 15 & -0.16 \\
\hline From bus 6 to bus 7 & -0.14 \\
\hline From bus 7 to bus 8 & -0.14 \\
\hline From bus 4 to bus 3 & -0.12 \\
\hline
\end{tabular}

\subsection{Verification of the effectiveness of the proposed closed-loop control}

Before applying the proposed control strategy, the effectiveness of the proposed closed-loop control in controlling the power flow is tested on selected transmission lines. During this test, the detection block $B_{D i}$ (see Fig. 4) is not necessary, in other words, the measured power of the selected line is used directly as indicated in equations (7) and (8). The control is tested on two lines with negative sensitivity indices (one line between buses 3 and 6 and the line between buses 15 and 8) and on one line with positive sensitivity index (the line between buses 1 and 2). The results obtained for the three selected lines are shown in Fig. 9, Fig. 10 and Fig. 11 respectively. As can be seen from these figures, after its activation at $t=2$ seconds, the closedloop control works well and controls the power flow through the selected lines at the given references. When a step change is applied to the reference at $t=4$ seconds, the closed-loop control acts accordingly and changes the DC power to achieve the desired power flow control. The controller's speed of response increases with the sensitivity index value, as can be seen from those three figures.

\subsection{Application of the control when there is a line outage}

In order to test the control when there is a line outage, one line between buses 6 and 9 is tripped at $t=2 \mathrm{~s}$ without reclosure. This outage greatly increases the loading level of the 
remaining line between buses 6 and 9. This is because, after the outage, almost the entire power in the tripped line is redistributed to the remaining line, according to circuit laws. To test the control strategy, it was assumed that the remaining line has a limit of $1950 \mathrm{MW}$, and $1850 \mathrm{MW}$ was chosen as a margin point for this line. It should be noted that these values are only used to test our control strategy (i.e. the limits chosen in this study are not the limits of the real system).

Fig. 12 shows the system responses for the above contingency for both cases with DC power control (curves WPC) and without DC power control (curves NPC). When the HVDC is transferring a constant amount of power (NPC), it is clear from Fig 12(a) that the power through the remaining line between buses 6 and 9 exceeds the limit value and stabilizes at approximately 2130 MW. However, when the control strategy is applied, the DC power (Fig 12(b)) is increased to reduce the loading of the remaining line and keep its power at the margin point (the green dashed line), as shown in Fig 12(a). To show the importance of the low-pass filter in the control system, the waveforms of $\Delta I_{D C}$ before and after the filter are shown in the figure.

As a second test, a double contingency is considered, where the two lines between buses 6 and 9 are tripped simultaneously at $t=2 s$ without reclosure. This contingency greatly increases the loading level of the lines between buses 6 and 7 and between buses 7 and 8 . The further outage of one of these lines could cause cascading outages leading to total blackout because large amounts of power will be redistributed to the other lines. Therefore, it is very important to protect these lines from overloading and reduce the risk of cascading outages. The HVDC link will act to relieve overload on the first line that reaches its loading limit. At the same time, the loading of the other lines will remain constant and below its limit. To test the control strategy, let us suppose that the lines between buses 6 and 7 are identical and have a limit of $2200 \mathrm{MW}$ each. Fig. 13 shows the system responses for this double contingency. When the control strategy is not applied, it is clear from Fig. 13(a) that the power through the lines between buses 6 and 7exceeds the limit value and stabilizes at approximately $2350 \mathrm{MW}$. With the proposed 
controller in action, it can be observed that the overload is successfully relieved within one second and the power flow is maintained at the specified margin point (2100 MW). At the same time the applied control also reduces the loading level of the lines between buses 7 and 8 as shown in Fig 13(b). Since the three parallel lines between buses 6 and 7 and between buses 7 and 8 are identical, the power through only one parallel line is shown in the figure.

\section{Discussion}

Usually HVDC links operate at their rated power. Thus, the increase in DC power during emergency situation depends on the overload capability offered by the HVDC links. The overload capability is subject to the thermal rating of the HVDC equipment and differs from one HVDC to another. However, the interaction between DC and AC systems may impose a DC power transfer limit lower than the actual overload capability of the HVDC link. The major phenomenon resulting from the AC/DC interactions and which can limit DC power transfer is the risk of AC voltage instability at the HVDC terminal, particularly in low SCR (Short-Circuit Ratio) applications. For given system conditions, an HVDC link always has a maximum power transfer limit which is related to the well known problem of AC voltage collapse due to the coupling between AC voltage and DC power variations [62-67]. Thus, an assessment of the phenomena to indicate any power transfer limitations or increased available power margins and associated critical voltage levels should be carried out when an HVDC is to be used as an emergency measure. A number of analytical techniques using system indices such as Maximum Available Power (MAP), Voltage Stability Factor (VSF) and Control Sensitivity Index (CSI) have been proposed to analyse voltage stability problems at HVDC terminals [64-66]. These techniques are very useful for assessing DC power capability and the need for AC voltage control when DC power varies. This means that the reactive power compensating devices in some cases must be over-sized to provide adequate control over AC voltage at overload capability. Since the reactive power requirement varies with the active power transfer, shunt 
capacitors are normally subdivided and switched in steps by circuit breakers depending on the transmitted power and the needs of the AC network. If the HVDC power suddenly increases in response to an emergency control, the sequential switching-in of shunt capacitors can not catch up with the rapid increase in reactive power consumption of the converter [68]. This delay in reactive power consumption (in practice 100-300 ms) may cause a drop in the AC voltage at the HVDC terminal for a short period $[63,68]$. On the other hand, reactive power compensation in a discontinuous manner causes variations of the AC voltage, particularly for systems with low SCR [63]. To avoid such problems, additional AC equipment such as synchronous compensators, static var compensators or STATCOMs could be required to provide effective reactive power and voltage control. However, these devices tend to incur additional investment and maintenance costs to the HVDC system hence compromising its economic advantage $[62,63,68]$.

In practice, when designing wide-area protection and control strategies, two important factors must be kept in mind: communication time delays and remote control signal loss. With modern PMUs interconnected using fiber-optic or satellite-based technology, communication delays are in the range of $100-400$ ms [55,69]. For transient and dynamic stabilities improvement, the time delays could potentially impact the controller performance and therefore they need to be taken into account in the design stage [55]. However, for relieving overloads of transmission lines, a time delay in the range of milliseconds is very acceptable to initiate a control action before the protection system acts even for severe overloads. On the other hand, with regard to the loss of the remote control signal or any failure that prevent emergency control from operating, two situations arise. In the first situation, the emergency control is used as a supplementary line of defense to preventive control, i.e. the emergency control acts only for worse cases such as N-2 contingency situations. However, this situation does not encourage the TSOs (Transmission System Operators) to invest in emergency controls based on wide-area signals. TSOs want to implement control strategies that allow higher power 
transfers and operating economies [3]. This leads to the second situation: the emergency control is used in addition to the preventive control to fulfill the N-1 criterion, as explained in Section 2. The emergency control is introduced here to reduce the high use of preventive actions, which contribute to a reduction in operating cost, while maintaining $\mathrm{N}-1$ security as shown by several studies $[4,5,10]$. In this situation, the effectiveness and reliability of emergency control, especially communication infrastructures, is a crucial issue. The benefit of the proposed control clearly appears in this situation. Unlike methods that are based on sensitivity computations which require high volume and variety of data, the proposed control does not require a large amount of data, which is very advantageous in term of its reliability. Indeed, the acquisition and processing of a large amount of data requires an information management system and other resources which further increase the cost and complexity of the system. With the proposed control, the power through the line of concern is the only information needed. This means that if from a set of AC lines in which the HVDC line would have an impact there are only a few critical lines that need to monitor and control their power flows, the power through these lines are the only necessary information. And, furthermore, if these lines are close to the HVDC link, that would be very useful since the proposed control can now be implemented at a local level based on local measurements, which offers a significant advantage in terms of reliability. One of the crucial issues regarding the proposed control is the selection of the appropriate HVDC link to relieve the detected overload (i.e. the HVDC that can produce the largest power flow change across the line of concern). The off-line analysis, proposed in the paper, which consists of selecting and ordering (from greatest to least) HVDC links according to their effects on line flows would be useful for systems where power flow patterns are relatively stable and predictable. An example of such systems is when the HVDC links and AC lines of concern are used to transmit power from the main power production facilities to the main loading areas, such as the systems shown in Fig. 6 and Fig. 7. However, in a highly meshed interconnected system where power flows patterns are more volatile and less predictable, using a fixed list 
becomes unreliable for real-time operation. Therefore, a more intelligent system to select the suitable HVDC link is required. Expert systems such as those proposed in $[18,30,31,58,59]$ are very ideal for this purpose and can greatly improve the selection process.

\section{Conclusion}

A closed-loop control strategy is proposed for HVDC links to relieve, in real-time, transmission lines overloads during emergency situations. The control scheme is implemented by adding a control signal to the DC current reference of the rectifier current regulator. With the proposed closed-loop scheme, the HVDC link can control the power flow on AC transmission lines at the given limits without the need to calculate the sensitivities indices of the transmission lines. The only information required is a continuous monitoring of the power through the line of concern. The effectiveness of the proposed method has been evaluated under various disturbances scenarios using a detailed simulation model. With the proposed control strategy, HVDC links can effectively contribute to improve the security of hybrid AC/DC interconnection systems. The method could be useful when the system is secure according to the $\mathrm{N}-1$ criterion but is operating under stress because of heavy power transfers, i.e. the method can be used to fulfill the N-1-1 criterion. Due to its real-time capability; the proposed method can even be used to fulfill the N-1 criterion (i.e. the corrective N-1 security criterion). Because it does not require large amounts of input data, the proposed method is simple to implement and can be used for all hybrid AC/DC systems. With this control strategy, the HVDC makes the interconnected power system more reliable, secure and economic. Therefore, this approach is an important step towards the development of future smart grids.

The proposed control strategy can also be applied to other power flow control devices such as FACTS devices and phase-shift transformers which is the focus of the authors' future work. 


\section{References}

[1] Real-Time Stability in Power Systems, Techniques for Early Detection of the Risk of Blackout. Editor: Savu C. Savulescu; 2nd Edition, Springer; 2014.

[2] L. Wehenkel and M. Pavella "Preventive vs. emergency control of power systems", IEEE PES Power Systems Conference and Exposition, New York, 2004.

[3] D. Kirschen, G. Strbac, "Why Investments Do Not Prevent Blackouts," The Electricity Journal, pp. 29-36, March 2004.

[4] A.J. Monticelli, M.V.P. Pereira, S. Granville, Security-constrained optimal power flow with post-contingency corrective rescheduling, IEEE Trans. Power Syst. 2 (1) (1987) 175-182.

[5] L. Roald, S. Misra, T. Krause, and G. Andersson, " Corrective Control to Handle Forecast Uncertainty: A Chance Constrained Optimal Power Flow", IEEE Trans. Power Syst; 2016.

[6] F. Capitanescu, J. Martinez Ramos, P. Panciatici, D. Kirschen, A. Marano Marcolini, L. Platbrood, and L. Wehenkel, "State-of-the-art, challenges, and future trends in security constrained optimal power flow," Electric Power Systems Research, vol. 81, no. 8, pp. 17311741, 2011.

[7] M. Vrakopoulou, S. Chatzivasileiadis, and G. Andersson, "Probabilistic security-constrained optimal power flow including the controllability of hvdc lines," in Innovative Smart Grid Technologies Europe (ISGT EUROPE), 2013 4th IEEE/PES, Oct 2013, pp. 1-5.

[8] R. Yang, G. Hug, "Potential and Efficient Computation of Corrective Power Flow Control in Cost vs. Risk Trade-Off" IEEE Trans. Power Syst., vol. 5, no. 4, pp. 2033-2043, 2014.

[9] Zarate-Mihano, R., Conejo, A.J., Milano, F.: ‘OPF-based security redispatching including FACTS devices', IET Gener. Transm. Distrib. J., 2008, 2, (6), pp. 821-833

[10] Marinakis, M. Glavic, and T. Van Cutsem, "Minimal reduction of unscheduled flows for security restoration: Application to phase shifter control,” IEEE Trans. Power Syst., vol. 25, no. 1, pp. 506-515, Feb. 2010.

[11] Shao, W., Vittal, V.: 'LP-based OPF for corrective FACTS control to relieve overloads and voltage violations', IEEE Trans. Power Syst., 2006, 21, (4), pp. 1832-1839

[12] S.C. Muller, U. Hager, C. Rehtanz, A multiagent system for adaptive power flow control in electrical transmission systems, IEEE Trans. Ind. Inf. 10 (4); 2014, 2290-2299.

[13] Task Force on Recent Blackout Experience, Mitigation, and Role of New Technologies, "Blackout Experiences and Lessons, Best Practices for System Dynamic Performance, and the Role of New Technologies", IEEE PES Special Publication 07TP190, July 2007.

[14] C. W. Taylor, D. C. Erickson, K. E. Martin, R. E. Wilson, and V. Venkatasubramanian, " WACS—Wide-Area Stability and Voltage Control System: R\&D and Online Demonstration," Proceedings of the IEEE, vol. 93, pp. 892-906, 2005.

[15] T. K. P. Medicherla, R. Billinton, and M. S. Sachdev, "Generation rescheduling and load shedding to alleviate line overloads—Analysis," IEEE Tran PAS-98, pp. 1876-1884, 1979.

[16] Kuppurajulu, "An emergency control algorithm for real-time applications", IEEE Trans PAS, 1985.

[17] Shandilya, H. Gupta and J. Sharma, "Method for generation rescheduling and local shedding to alleviate line overloads using local optimization," IEE Proceedings, Vol. 140, No. 5, Sep. 1993, Page(s): 337-342.

[18] Lenoir, L., Kamwa, I., Dessaint, L.A.: 'Overload alleviation with preventive-corrective static security using fuzzy logic', IEEE Trans. Power Syst., 2009, 24, (1), pp. 134-145

[19] J.N. Wrubel, P.S. Rapcienski, K.L. Lee, B.B. Gisin, G.W. Woodrell, Practical experience with corrective switching algorithm for on-line applications, IEEE Trans. Power Syst. 12 (1) (1996) 415-421.

[20] J.G. Rolim, L.J.B. Machado, A study of the use of corrective switching in transmission systems, IEEE Trans. Power Syst. 14 (1) (1999) 336-341.

[21]W. Shao, V. Vittal, Corrective switching algorithm for relieving overloads and voltage violations, IEEE Trans. Power Syst. 20 (4) (2005) 1877-1885.

[22] Thanikachalam ; V. T. Sulzberger ; P. Van Olinda ; J. N. Wrubel, "On-line operation of phase shifters using energy control center computers", IEEE Tran PAS-93, pp. 1563-1571, 1974.

[23] J. A. Momoh, J. Z. Zhu, G. D. Boswell, and S. Hoffman, "Power system security enhancement by OPF with phase shifter," IEEE Trans. Power Syst., vol. 16, no. 2, pp. 287-293, May 2001.

[24] N. S. Dhaliwal, J. B. Davies, D. A. N. Jacobson, R. Gonzalez, " Use of an integrated ac/dc special protection scheme at Manitoba hydro", CIGRE Technical Report, Report no: B5-206; 2006. 
[25] N. Li, Y. Xu, and H. Chen, "FACTS-based power flow control in interconnected power systems," IEEE Trans. Power Syst., vol. 15, no. 1, pp. 257-262, Feb. 2000.

[26] S. H. Song, J. U. Lim, S. W. Jung, and S. I. Moon, "Preventive and corrective operation of FACTS devices to cope with a single linefaulted contingency," Power Engineering Society General Meeting, IEEE, vol.1, pp. 837 - 842, Jun. 2004.

[27] P. Guha Thakurta, R. Belmans, and D. Van Hertem, "Risk-based management of overloads caused by power injection uncertainties using power flow controlling devices,", IEEE Transactions on Power Systems, vol. 30, no. 6, pp. 3082-3092, Nov 2015.

[28] Z. Jiao, X. Wang, H. Gong, " Wide area measurement/wide area information-based control strategy to fast relieve overloads in a selfhealing power grid", IET Gener. Transm. Distrib., 2014, Vol. 8, Iss. 6, pp. 1168-1176

[29] Oudalov, R. Cherkaoui, A.J. Germond, M. Emery, “Coordinated Power Flow Control by Multiple FACTS Devices”, Proc. of the IEEE Power Tech 2003 Conference, Bologna, Italy, June 23-26, pp. 48-52

[30] K. R. W. Bell, A. R. Daniels, and R. W. Dunn, “Alleviation of transmission system overloads using fuzzy reasoning," Fuzzy Sets Syst., vol. 102, pp. 41-52, 1999.

[31] Oudalov and P. Korba, "Fuzzy gain scheduling technique for power flow control", Int. J. Computer Applications in Technology, Vol. 27, 2006.

[32] P. R. Bijwe, D. P. Kothari, and L. D. Arya, “Alleviation of line overloads and voltage violations by corrective rescheduling," Proc. Inst. Elect. Eng., Gen., Transm., Distrib., vol. 140, pp. 249-255, 1993.

[33] Monitoring, Control and Protection of Interconnected Power Systems. Editors: Ulf Häger, Christian Rehtanz, Nikolai Voropai; Springer; 2014.

[34]CIGRE Joint Working Group C4/B4/C1.604. Influence of Embedded HVDC Transmission on System Security and AC Network Performance. Technical Brochure 536; 2013.

[35] L. Carlsson, "HVDC A "firewall" against disturbances in high-voltage grids," ABB Review, 2005.

[36] Final Report on the August 14, 2003 Blackout in the United States and Canada: Causes and Recommendations, US-Canada Power System Outage Task Force, Apr. 2004.

[37] W. Breuer, V. Hartmann, D. Povh, D. Retzmann and E. Teltsch, "Application of HVDC for large power system interconnections," CIGRE paper B4-106, Paris, 2004.

[38] G. Andersson, P. Donalek, R. Farmer, N. Hatziargyriou, I. Kamwa, P. Kundur, N. Martins, J. Paserba, P. Pourbeik, J. Sanchez-Gasca, R. Schulz, A. Stankovic, C. Taylor, and V. Vittal, "Causes of the 2003 major grid blackouts in North America and Europe, and recommended means to improve system dynamic performance," IEEE Trans. Power Syst., vol. 20, pp. 1922-1928, 2005.

[39] I. Dobson, B.A. Carreras, V.E. Lynch, and D.E. Newman, "Complex systems analysis of series of blackouts: cascading failure, critical points, and self-organization," Chaos, vol. 17, pp. 1-13, 2007.

[40] Union for the Coordination of Transmission of Electricity (UCTE). Final report on system disturbance on 4 November 2006. Tech Rep; 2007.

[41] Union for the Coordination of Transmission of Electricity. Final Report of the Investigation Committee on the 28 September 2003 Blackout in Italy. UCTE Report; 2004.

[42] IEEE Committee Report, "Dynamic performance characteristics of north American HVDC systems for transient and dynamic stability evaluations," IEEE Trans. Power App. Syst, Vol. PAS-100, pp. 3356-3364, 1981.

[43] M. Benasla, T. Allaoui, M. Brahami, M. Denaï, V. K. Sood. HVDC links between North Africa and Europe: Impacts and benefits on the dynamic performance of the European system. Renewable and Sustainable Energy Reviews, vol. 82, pp. 3981-3991, 2018.

[44] Benasla M, Allaoui T, Brahami M, Boudali A. Benefits of HVDC for reducing the risk of cascading outages and large blackouts in AC/DC hybrid grid. In: Proceedings of the3rd International Conference on Control, Engineering \& Information Technology (CEIT), 2015; pp. 1-6.

[45] IEEE Committee Report. HVDC controls for system dynamic performance. IEEE Trans Power Syst 1991;6:743-52.

[46] R. J. Meredith, P. C. S. Krishnayya, S. Lefebvre, V. K. Sood, R. Lee and G. Langewisch. "Methodology for integration of HVDC links in large AC systems - Phase 1: Reference Manual”. Electrical Power Research Institute, Final Report EL - 3004, RP 1964-1, March, 1984.

[47] Sood VK. HVDC and FACTS Controllers - Applications of Static Converters in Power Systems. Boston: Kluwer; 2004.

[48] Vural AM. Contribution of high voltage direct current transmission systems to inter-area oscillation damping: A review. Renew Sustain Energy Rev 2016;57:892-915.

[49] Cresap RL, Mittelstadt WA. Small-signal modulation of the Pacific HVDC intertie. IEEE Trans Power Appar Syst 1976;PAS-95:536-41.

[50] Smed T, Andersson G. Utilising HVDC to damp power oscillations. IEEE Trans Power Deliv 1993;08:620-27. 
[51] Kamwa I, Grondin R, Asber D, Gingras JP, Trudel G. Large-scale active-load modulation for angle stability improvement. IEEE Trans Power Syst 1999;14:582-90.

[52] X. Aidong, W. Xiaochen, H. Chao, J. Xiaoming, and L. Peng, "Study on Overload Capability and Its Application of HVDC Transmission System in China Southern Power Grid," in proc. 2007 IEEE PES Power Africa Conf., pp 1-4.

[53] M. D. Ilic, E. h. Allen, J. w. Chapman, C. A. King, J. H. Lang, E. Litvinov, " Preventing Future Blackouts by Means of Enhanced Electric Power Systems Control: From Complexity to Order," Proceedings of the IEEE, vol. 93, pp. 1920-1941, 2005.

[54] Wide-Area Monitoring of Interconnected Power Systems. A. R. Messina; The Institution of Engineering and Technology; 2015.

[55] Interconnected Power Systems Wide-Area Dynamic Monitoring and Control Applications. Y. Li, D. Yang, F. Lin, Y. Cao, C. Rehtanz, Springer; 2016.

[56] Application of Time-Synchronized Measurements in Power System Transmission Networks. M. Kezunovic, S. Meliopoulos, V. Venkatasubramanian, V. Vittal. Rehtanz, Springer; 2014.

[57] IEEE Committee Report, "A description of discrete supplementary controls for stability," IEEE Trans. Power App. Syst., vol. PAS-97, pp. 149-165, 1978.

[58] K. R. W. Bell, A. R. Daniels, and R. W. Dunn, "Modelling of operator heuristics in dispatch for security enhancement," IEEE Trans. Power Syst., vol. 14, no. 3, pp. 1107-1113, Aug. 1999.

[59] N. Udupa, G. K. Purushothama, K. Parthasarathy, and D. Thukaram, "A fuzzy control for network overload alleviation,” Int. J. Elect. Power Energy Syst., vol. 23, no. 2, pp. 119-128, 2001.

[60] Ghahremani, E., Kamwa, I., "Local and Wide-Area PMU-Based Decentralized Dynamic State Estimation in Multi-Machine Power Systems", IEEE Trans. Power Syst., 2016, 31, (1), pp. 547-562

[61] IEEE Task Force on Dynamic Average Modeling. Dynamic Average-Value Modeling of CIGRE HVDC Benchmark System. IEEE Trans Power Deliv. 2014;29:2045-2054.

[62] CIGRE Working Group 14.05. On voltage and power stability in AC/DC systems. Technical Brochure 222, CIGRE; 2003.

[63] HVDC TRANSMISSION Power Conversion Applications in Power Systems. C. Kim, V. K. Sood, G. Jang, S. Lim and S. Lee, John Wiley; 2009.

[64] A.E. Hammad, W. Kuhn, "A computation algorithm for assessing voltage stability at ac/dc interconnections", IEEE Transactions on Power Systems, vol.1 no.1, pp.209-215, 1986.

[65] Pilotto, L. A. S., Szechtman, M. and Hammad, A. E; "Transient AC voltage related phenomena for HVDC schemes connected to weak AC systems", IEEE Trans. Power Delivery Vol. 7 , No.3 Jul 1992 , pp 1396-1404.

[66] Franken, B., Andersson, G., “Analysis of HVDC Converters Connected to Weak AC Systems”, IEEE Transactions on Power Systems, vol.5 no.1, pp.235-242, Feb.1990.

[67] C. Hatziadoniu, G. D. Galanos, "Interactions between the ac voltages and dc current in weak ac/dc interconnections”, IEEE Transactions on Power Delivery, vol.3 no.4, pp.2092-2101, 1988.

[68] CIGRE Working Group 14.05. Interaction between HVDC converters and nearby synchronous machines. Technical Brochure 119, CIGRE; 1997.

[69] Kamwa, I., Grondin, R., Hebert, Y., "Wide-area measurement based stabilizing control of large power systems-a decentralized/hierarchical approach", IEEE Trans. Power Syst., 2001, 16, (1), pp. 136-153.

[70] J. Tu, H. Xin, Z. Wang, D. Gan, and Z. Huang, "On Self-Organized Criticality of the East China AC-DC Power System—The Role of DC Transmission," IEEE Trans. PowerSyst, vol. 28, pp. 3204-3214, 2013. 


\section{Figure captions}

Fig. 1. Two-Bus power system. (a) Unsecured operation (i.e. pure economic dispatch). (b) Operation under the N-1 security rule (i.e. security-constrained dispatch). (c) Security constrained dispatch with corrective action into account.

Fig. 2. Current controller.

Fig. 3. Power characteristics. (a) controlling the HVDC link with real-time closed-loop control. (b) Realtime set-point change of the HVDC link.

Fig. 4. Block diagram of the control strategy.

Fig. 5. Flow Chart illustrating the overload relief procedures in the proposed control strategy.

Fig. 6. Structure and power flow of the 2010 East China power system (ECPS) [70].

Fig. 7. Single-line diagram of simplified model of Hydro-Québec network and base case operating point. Loads are connected in the black buses. Lines with red color: $0.2<S_{i}<0.4$, lines with yellow color: $0.15<S_{i}<0.2$, lines with green color: $0.1<S_{i}<0.15$ and line with no color: no or negligible sensitivity.

Fig. 8. HVDC system.

Fig. 9. Verifying the closed-loop control on one line between buses 3 and 6. (a) Power flow in one line between buses 3 and 6 and the given reference. (b) DC power. (c) Control signal ( $\Delta I_{D C}$ ). (d) Rectifier and inverter firing angle orders.

Fig. 10. Verifying the closed-loop control on line between buses 15 and 8. (a) Power flow in line between buses 15 and 8 and the given reference. (b) DC power.

Fig. 11. Verifying the closed-loop control on line between buses 1 and 2. (a) Power flow in line between buses 1 and 2 and the given reference. (b) DC power.

Fig. 12. Tripping of one line between buses 6 and 9. (a) Power flow in the remaining line between buses 6 and 9. (b) DC power. (c) Control signal $\left(\Delta I_{D C}\right)$ after the filter. (d) Control signal $\left(\Delta I_{D C}\right)$ before the filter.

Fig. 13. Tripping of the two lines between buses 6 and 9. (a) Power flow in one line between buses 6 and 7. (b) Power flow in one line between buses 7 and 8. (c) DC power. (d) Control signal $\left(\Delta I_{D C}\right)$. 
Figure 1:

(a)

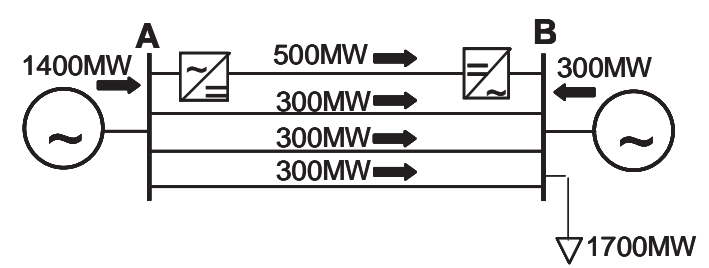

(b)

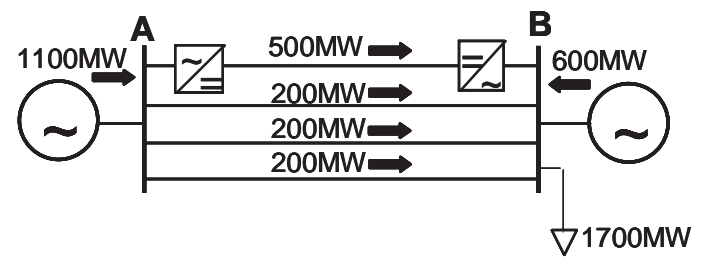

(c)

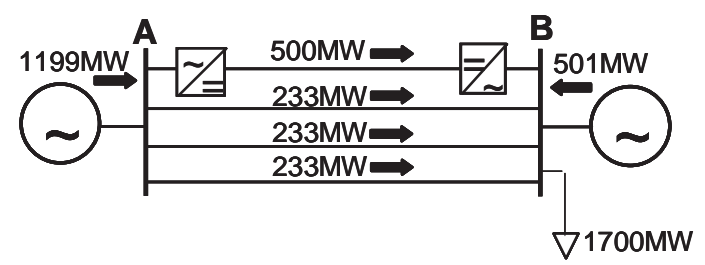

Figure 2:

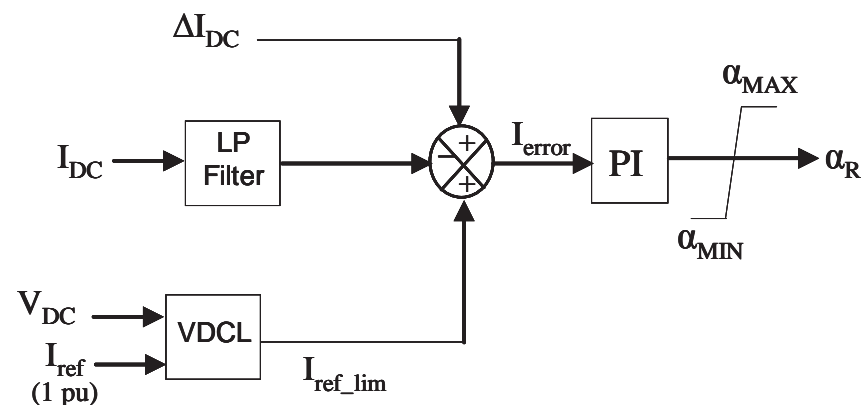


Figure 3:

(a)

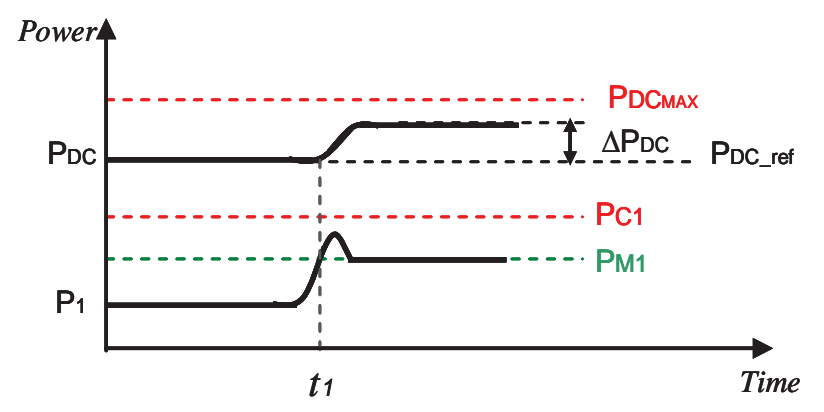

(b)

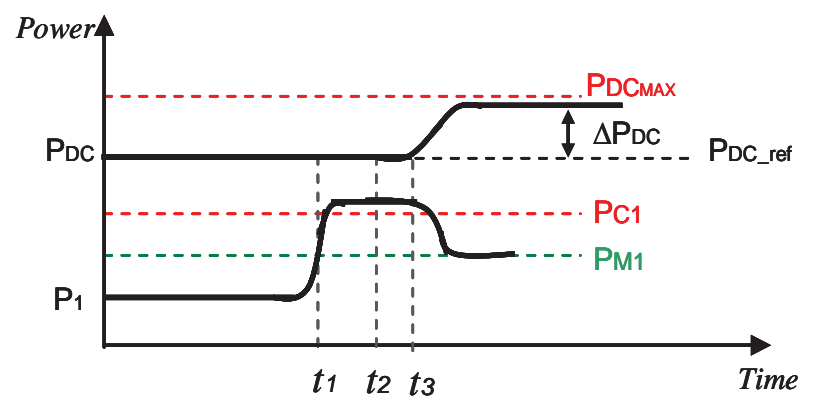

Figure 4:

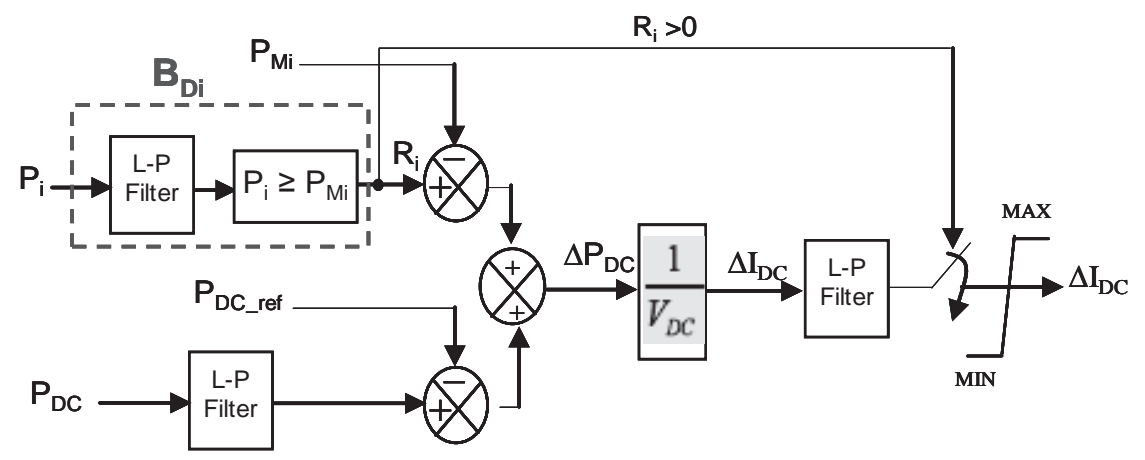


Figure 5:

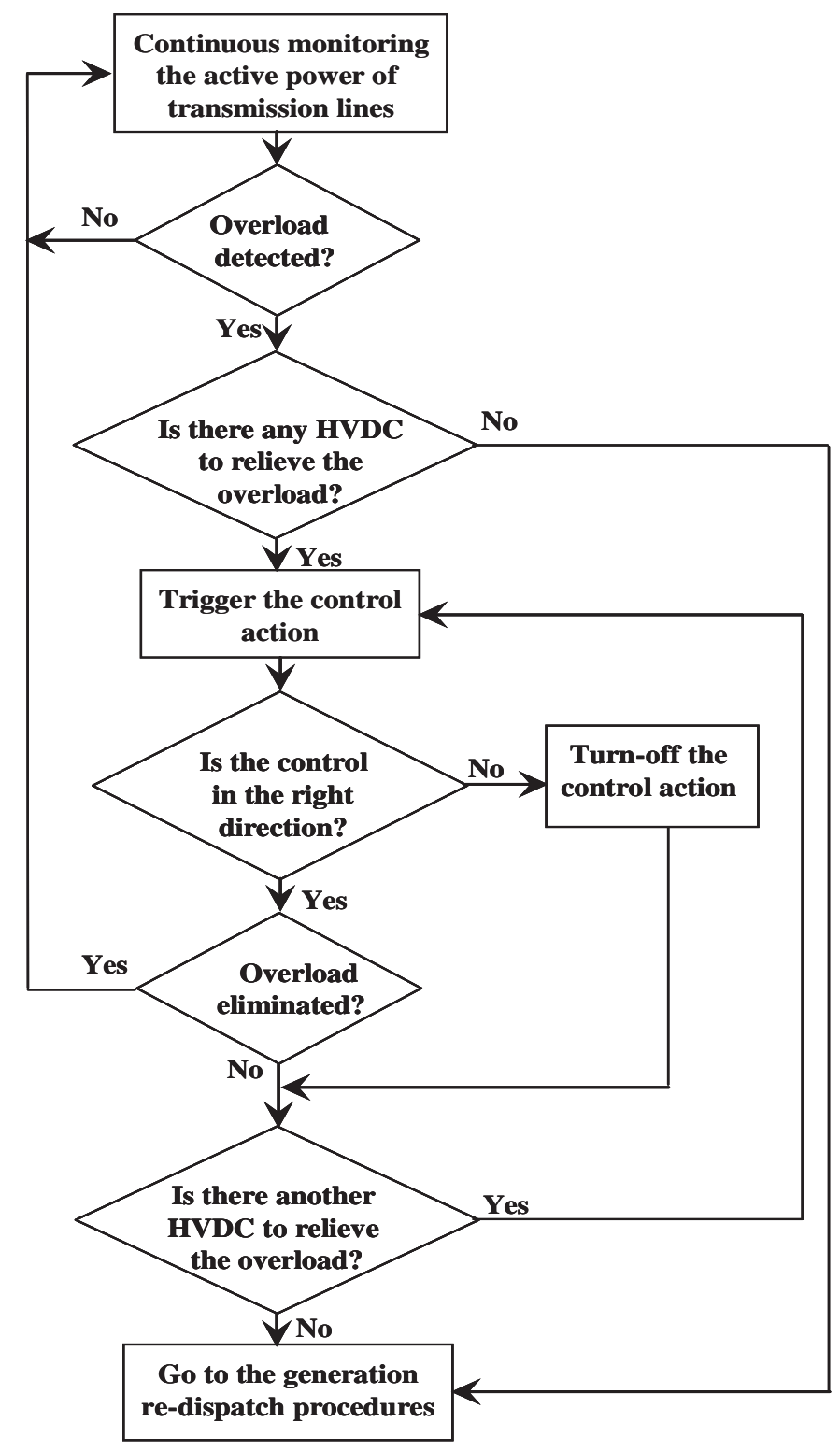

Figure 6:

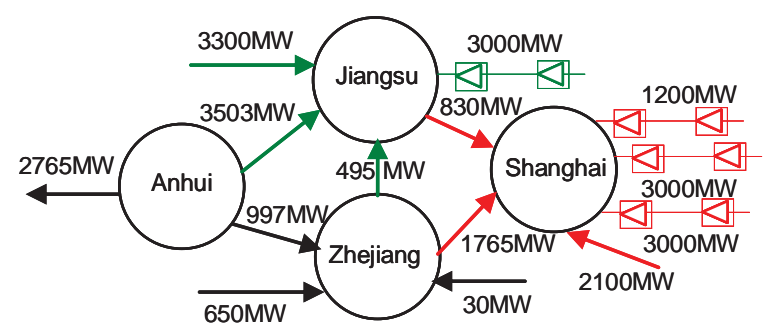


Figure 7:

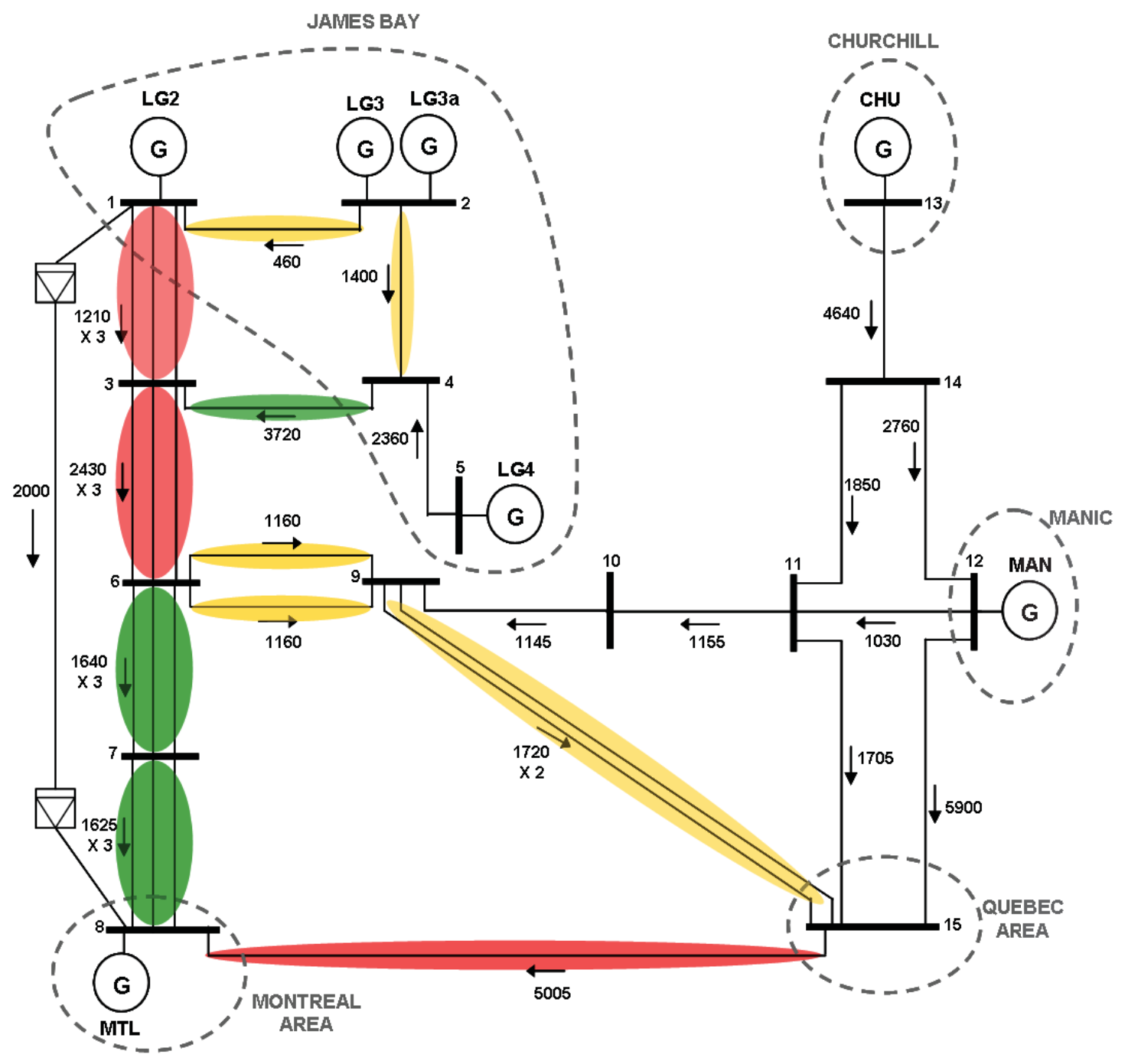

Figure 8:

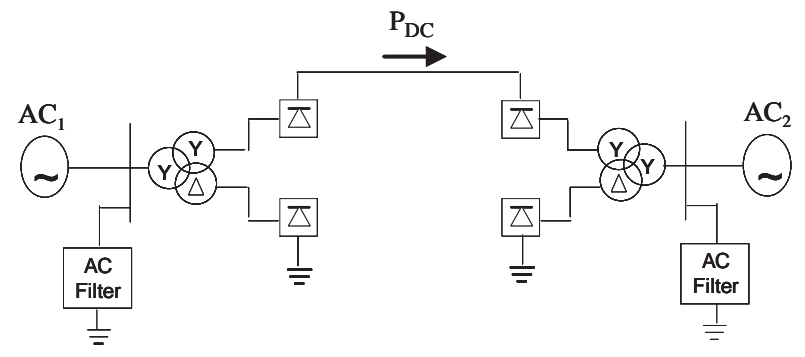


Figure 9:
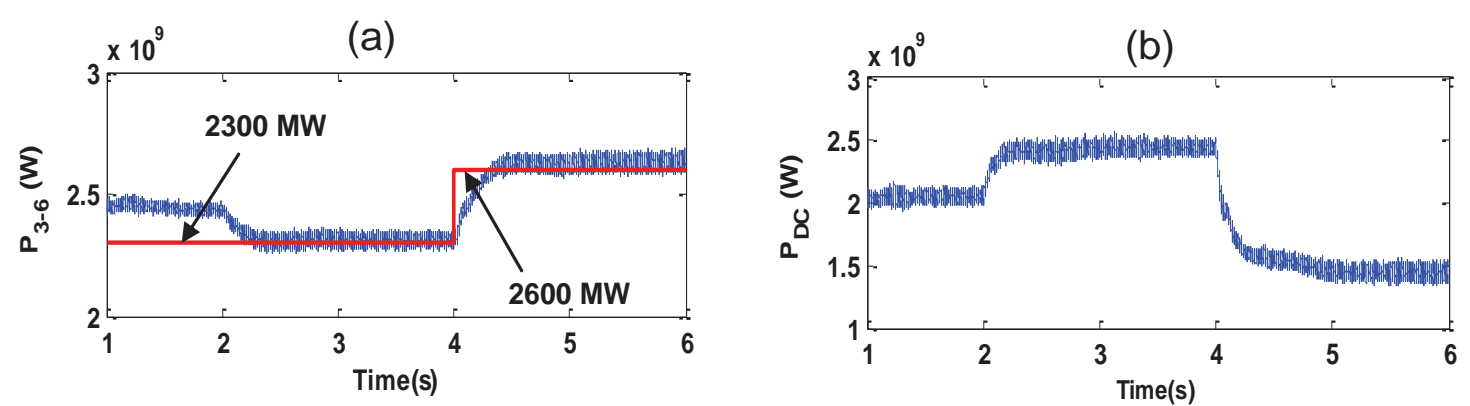

(c)

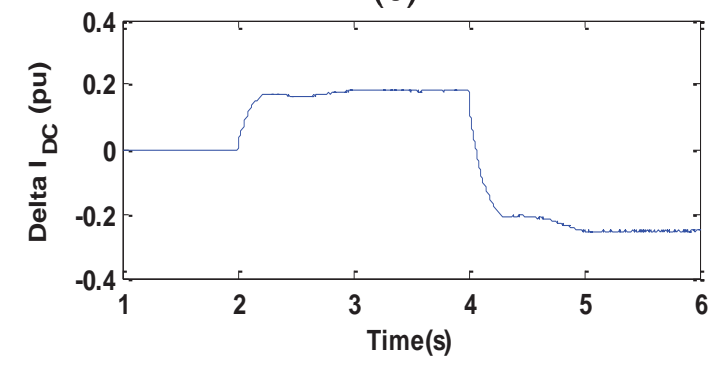

(d)

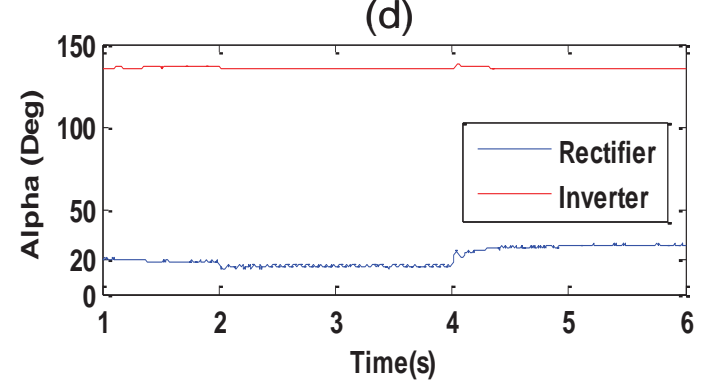

Figure 10:
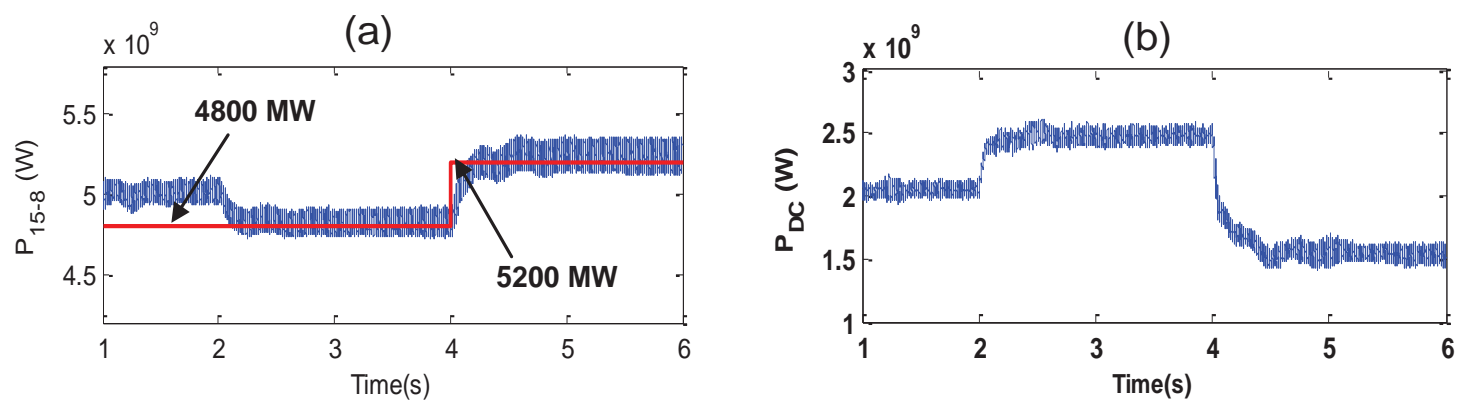

Figure 11:
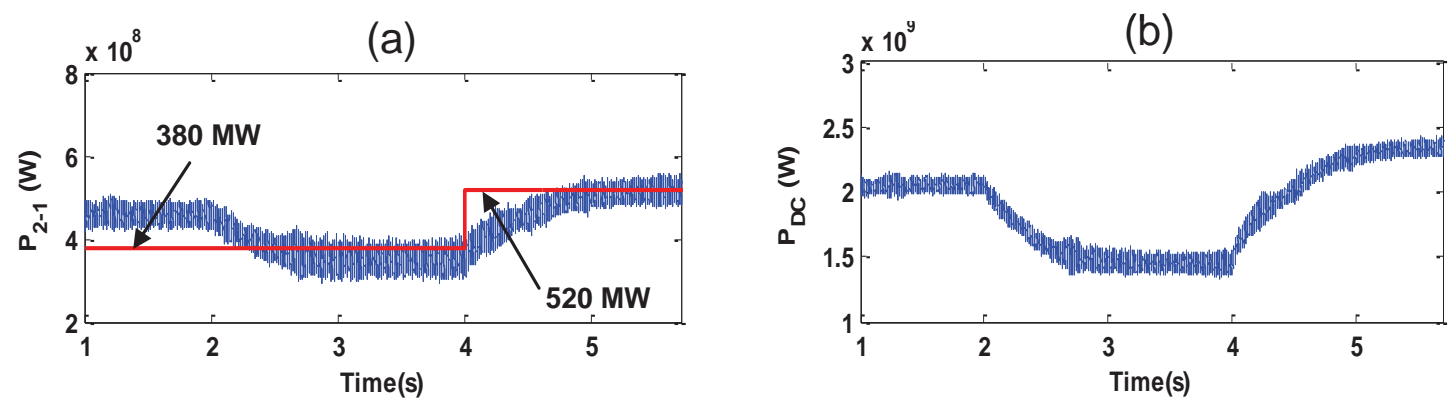
Figure 12:
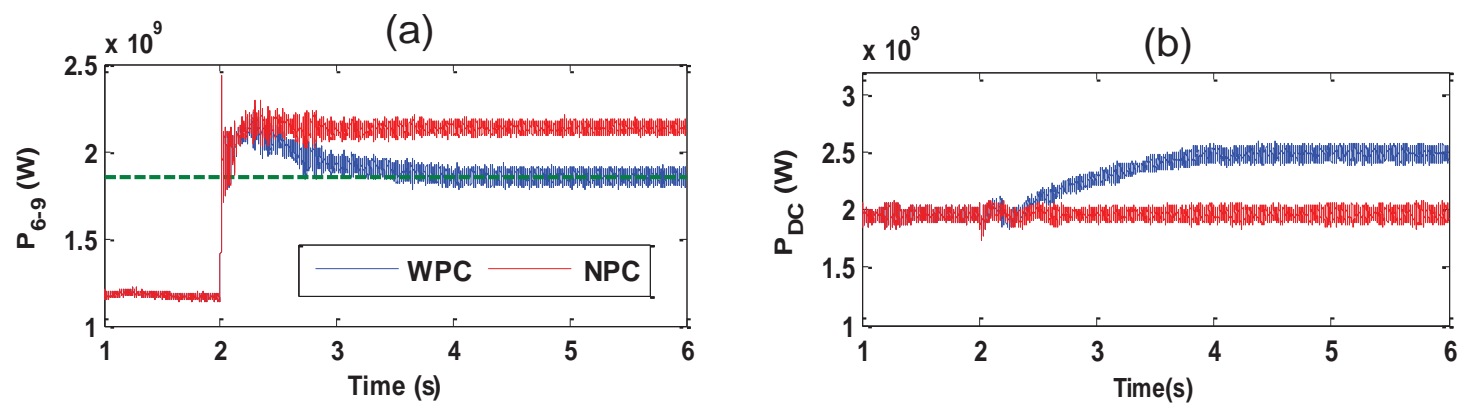

(c)

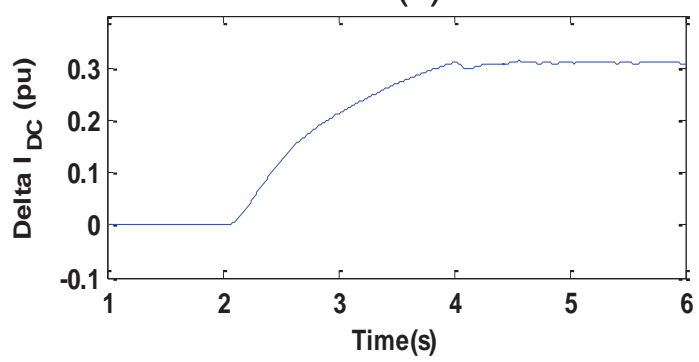

(d)

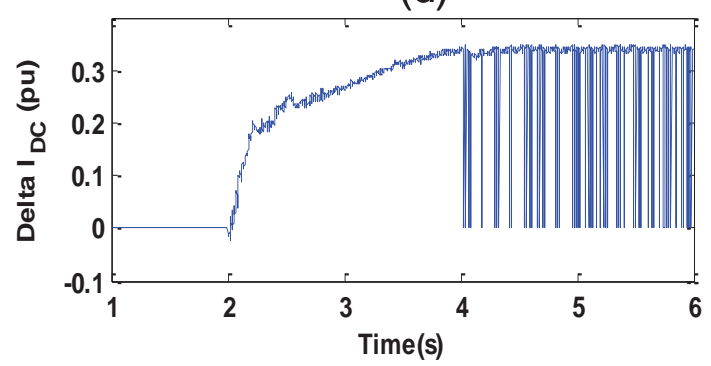

Figure 13:
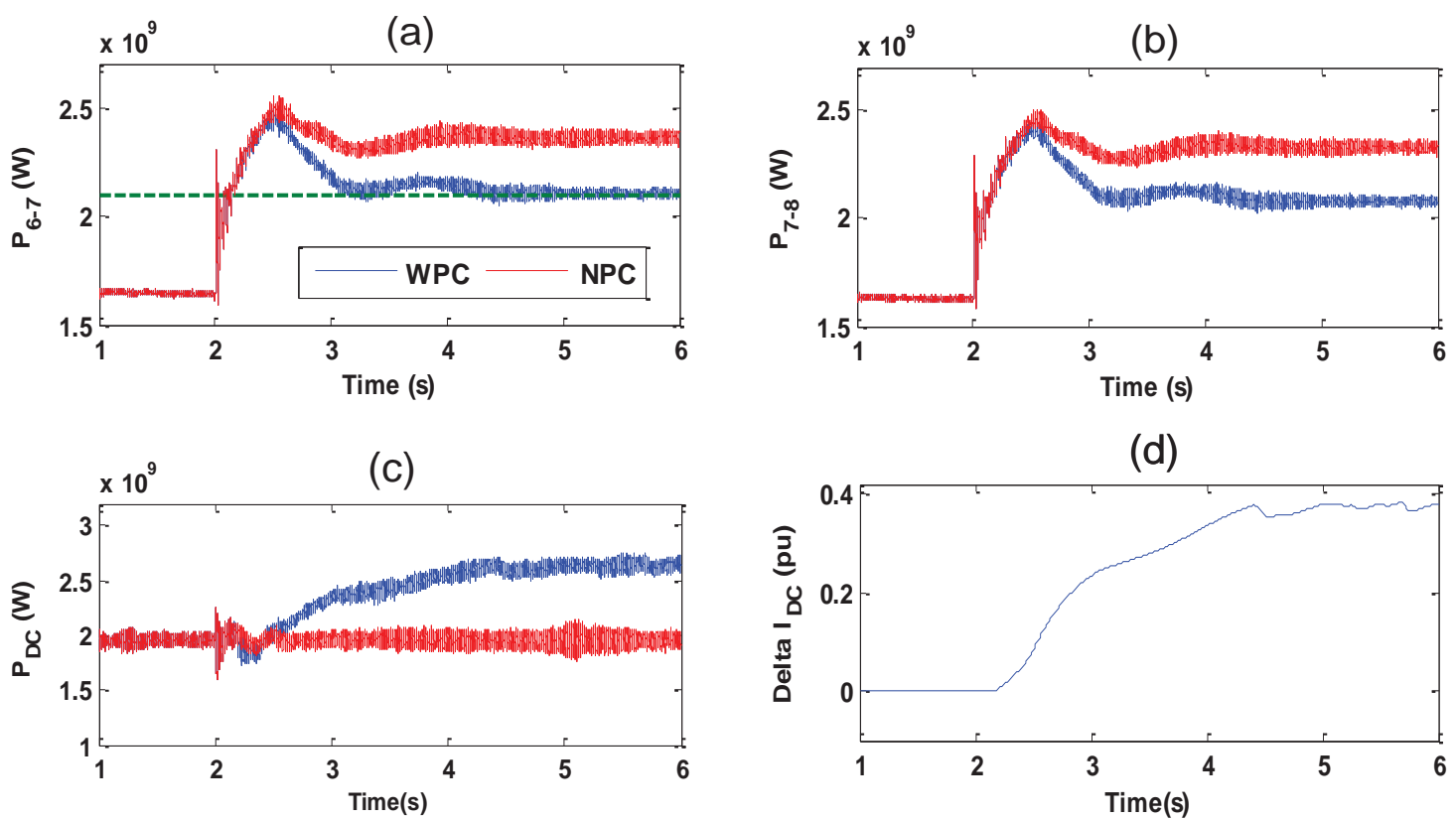

(d)

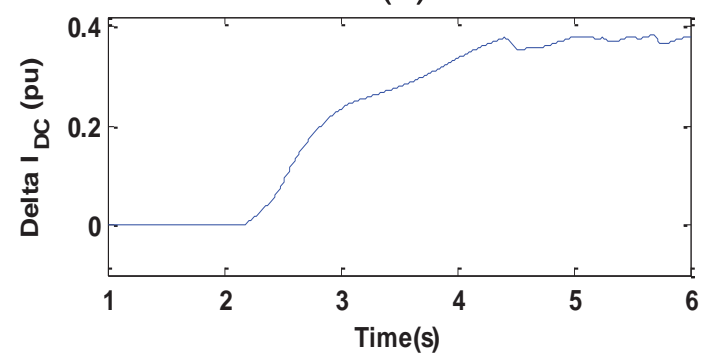

